\title{
Elevated Serum Fructosamine Concentration as an Index of Risk State of Abnormal Glucose Metabolism for Coronary Atherosclerosis
}

\author{
Naohito Tanabe ${ }^{1}$, Hideaki Toyoshima ${ }^{1}$, Senji Hayashi ${ }^{1}$, Kunio Miyanishi $^{1}$, \\ Akihiro Obata ${ }^{2}$, Makihiko Saeki ${ }^{2}$, Tomohiko Yamamoto ${ }^{3}$, \\ Nobuhiro Ozaki ${ }^{3}$, Yoshiaki Tanaka ${ }^{2}$, Toshiya Aizaki², \\ Tohru Izumi ${ }^{2}$ and Akira Shibata ${ }^{2}$
}

\begin{abstract}
To examine the usefulness of hyperfructosaminemia as an index of risk state of abnormal glucose metabolism for coronary atheroscrelotic disease, serum fructosamine concentration was compared between 130 male cases with coronary stenosis, aged 60 years or younger, and 260 age-matched male controls. Past history of diabetes mellitus (DM) and information on confounders such as serum lipid concentration, obesity, smoking habits, and family history of ischemic heart disease were obtained from all the subjects. There was no difference in frequency of the past history of DM between the cases $(8.5 \%)$ and the controls $(6.9 \%)$, but that of hyperfructosaminemia (cases : $36.2 \%$, controls : $15.0 \%$ ) was significantly higher in the cases than in the controls $(p<0.01)$. When confounding effects by other risk factors were adjusted by multiple logistic regression analysis, the odds ratio of the past history of DM $(1.19,95 \%$ confidence interval : $0.47 \sim 3.03$ ) was not significant, but that of hyperfructosaminemia (3.59, $95 \%$ confidence interval : $1.94 \sim 6.65$ ) was significant after the past history of DM was replaced by it. Thus, abnormal glucose metabolism evaluated by hyperfuctosaminemia was an independent coronary risk factor, although that evaluated by the past history of DM was not. These results suggest that serum fructosamine is a useful index of coronary risk state related to abnormal glucose metabolism. J Epidemiol, $1992 ; 2$ : 105-110.
\end{abstract}

coronary artery disease, risk factor, serum fructosamine, abnormal glucose metabolism, diabetes mellitus

Abnormality of glucose metabolism such as impaired glucose tolerance and diabetes mellitus (DM) has been known to be an important risk factor for coronary artery disease ${ }^{1-3)}$. In our previous study ${ }^{4}$, DM was also determined to be a coronary risk factor in the young men aged 40 years or younger, but was not in the elderly men aged 41 to 60 years $^{5)}$. In that study, however, information concerning an abnormality in the glucose metabolism had been given by the memory of participants as to the past history of DM, and by either the fasting plasma glucose level or the result of oral glucose tolerance test which were not performed in every subject. In addition, the past history of DM might have been more accurately screened in the controls than in the cases because majority of the former is thought to have received health check-up annually. This might be the reason that DM did not come out as the risk factor in the elderly in the previous study).

Thus in the present study, we tested reliability of the serum fructosamine concentration, well known as a good indicator of mean blood glucose level during 1 to 2 weeks before determination ${ }^{6-8)}$, as the objective index for evaluating abnormal glucose metabolism. Then, the importance of the abnormal glucose metabolism, estimated by serum fructosamine level, as a coronary risk factor was investigated, and the usefulness of

Received September 24, 1992 ; Accepted January 5, 1993.

${ }^{1}$ Department of Public Health and ${ }^{2}$ First Internal Medicine, Nigata University School of Medicine, Niigata, Japan. ${ }^{3}$ Division of Internal Medicine, Niigata Posts and Telecommunications Hospital, Niigata, Japan.

Address for correspondence: Hideaki Toyoshima, Department of Public Health, Niigata Universioy School of Medicine. 1-757 Asahimachi-dori Niigata 951, Japan. 
employing the serum fructosamine concentration to judge the risk state was evaluated in the young as well as in the elderly men.

\section{SUBJECTS AND METHODS}

Cases in this study were male patients who had suffered from myocardial infarction or angina pectoris. Coronary atherosclerosis was diagnosed by their first coronary angiography during the study period at one of eight major hospitals in Niigata Prefecture, Japan. All of them had at least one stenosis of more than $75 \%$ of luminal diameter in a coronary artery. 45 cases aged 40 years or younger were recruited during six years from 1984, and 99 cases, aged 41 to 60 years, during a one-year period from April of 1989 . In total 144 cases participated in this study. The body mass index (BMI) was calculated by height and weight which was measured at the time of hospitalization for examination of the coronary angiography. All cases were interviewed as to their medical histories such as past histories of DM and hypertension and their family history of ischemic heart disease in addition to their lifestyle through the use of a uniform questionnaire during the hospitalization or their visit to an outpatient office after discharge. A blood sample was taken at the time of the interview and the serum was stored below $-40^{\circ} \mathrm{C}$ until chemical analysis. In most of the 58 cases of acute myocardial infarction, interviews and blood drawings were performed after the discharge and in several cases, just before the discharge to avoid various effects of the treatment given during acute stage of the disease.

For each of the 144 cases two age-matched male controls, 288 in total, were randomly chosen from post office workers who were working in Niigata City, the capital of Niigata Prefecture, and had received annual health check-up in May of 1989, and from citizens who visited a private health center in Niigata City for health check-up. As a result, 207 post office workers, approximately one third of whom worked mainly outside of the post office, and 81 citizens were chosen. At the time of examination, BMI was calculated, information concerning medical history and lifestyle was obtained at the interview using the same questionnaire as used for the cases, and a blood specimen was drawn and stored in the same way as in the cases.

Concentrations of fructosamine, total cholesterol and high density lipoprotein cholesterol (HDLcholesterol) in the stored sera were determined during four consecutive days in September of 1991. Serum concentration of fructosamine was determined by a colorimetric method using a kit (Roche II, Roche Co., Switzerland), and that of cholesterol, by an enzymatic method. The HDL component was separated by a phospho-tungstate magnesium method. The serum level of triglyceride was not used for this study since not all subjects were fasting before blood was drawn. Fourteen cases in whom chemical analysis was not completed because of a lack of serum, and, hence, matched 28 controls were excluded from this study. Consequently, 130 cases and 260 controls were subjects for statistical analysis.

The criteria for abnormal health conditions treated as coronary risk factors in this paper were as follows. Serum concentration of fructosamine and body mass index were judged abnormally high when they were equal to or exceeded the value of the mean plus one standard deviation of control subjects ; $285 \mu \mathrm{mol} / 1$ for fructosamine and $25.7 \mathrm{~kg} / \mathrm{m}^{2}$ for body mass index. Hypercholesterolemia was determined when serum concentration of total cholesterol was $220 \mathrm{mg} / \mathrm{dl}$ or higher, and hypo-HDL-cholesterolemia, when the concentration was $40 \mathrm{mg} / \mathrm{dl}$ or less. Both current and ex-smokers were assumed to have a smoking habit. Presence of a past history of DM and hypertension, and a family history of ischemic heart disease was judged by answer to the interview. The subject was assumed to have a family history of ischemic heart disease when at least one of his parents or siblings had suffered from myocardial infarction or angina pectoris.

\section{STATISTICAL ANALYSIS}

Difference of mean values of coronary risk factors between the cases and the controls were tested by non-paired t-test. Difference of the proportional rate of those who had each risk factor in the cases and the controls was tested by chi-square test with Yates' continuity correction or by Fisher's exact probability test when the expected value was smaller than 5 . To estimate the odds ratio of each of the past history of DM and hyperfructosaminemia by adjusting for confoundings by other risk factors, multiple logistic regression analysis was used. In all statistical analyses, $\mathrm{p}<$ 0.05 was taken as a level of statistical significance and $0.05 \leqq p<0.10$ as that of borderline significance.

\section{RESULTS}

Mean values of coronary risk factors in the cases and the controls are shown in Table 1. Means of serum fructosamine (case : $278.0 \mu \mathrm{mol} / 1$, control : 262.1 $\mu \mathrm{mol} / \mathrm{l}$ ) and BMI (case: $24.0 \mathrm{~kg} / \mathrm{m}^{2}$, control : 23.0 $\left.\mathrm{kg} / \mathrm{m}^{2}\right)$ were significantly $(\mathrm{p}<0.05)$ higher in the cases than in the controls, and the mean of serum HDLcholesterol (case : $35.1 \mathrm{mg} / \mathrm{dl}$, control : $47.8 \mathrm{mg} / \mathrm{dl}$ ) was significantly lower in the cases. Means of age 
Table 1. Mean values and standard deviations of coronary risk factors in the cases $(n=130)$ and the controls $(n=260)$.

\begin{tabular}{lrcc}
\hline \multicolumn{1}{c}{ Coronary risk factors } & \multicolumn{1}{c}{ Cases } & Controls & $\mathrm{p}$ \\
\hline Age (years) & $48.4 \pm 9.0$ & $48.2 \pm 9.0$ & $\mathrm{~ns}$ \\
Serum fructosamine $(\mu \mathrm{mol} / \mathrm{l})$ & $278.0 \pm 52.1$ & $262.1 \pm 23.0$ & $<0.01$ \\
Serum total cholesterol $(\mathrm{mg} / \mathrm{dl})$ & $194.0 \pm 41.6$ & $192.8 \pm 38.6$ & $\mathrm{~ns}$ \\
Serum HDL-cholesterol $(\mathrm{mg} / \mathrm{dl})$ & $35.1 \pm 11.4$ & $47.8 \pm 15.2$ & $<0.01$ \\
Body mass index $\left(\mathrm{kg} / \mathrm{m}^{2}\right)$ & $24.0 \pm 2.7$ & $23.0 \pm 2.7$ & $<0.01$ \\
\hline
\end{tabular}

Five cases and four controls were excluded for comparison of body mass index because of a lack of information about their height and/or weight.

(case : 48.4 years, control : 48.2 years) and serum total cholesterol (case : $194.0 \mathrm{mg} / \mathrm{dl}$, control : $192.8 \mathrm{mg} / \mathrm{dl}$ ) were not different between the cases and the controls. Serum fructosamine well showed an approximate normal distribution both in the cases and the controls (Fig. 1)

Profiles of coronary risk factors in the cases and the controls are shown in Table 2. Although the rate of those who had a past history of DM was not different between the cases (8.5\%) and the controls (6.9\%), that of hyperfructosaminemics was significantly higher in the cases $(36.2 \%)$ than in the controls $(15.0 \%, p<0.01)$.

Confounders such as hypo-HDL-cholesterolemia $(p<0.01)$, smoking habit $(p<0.01)$, a past history of hypertension $(\mathrm{p}<0.01)$ and the family history of ischemic heart disease $(p<0.05)$ were present significantly more often in the cases than in the controls. The frequency of obesity also tended to be higher in the

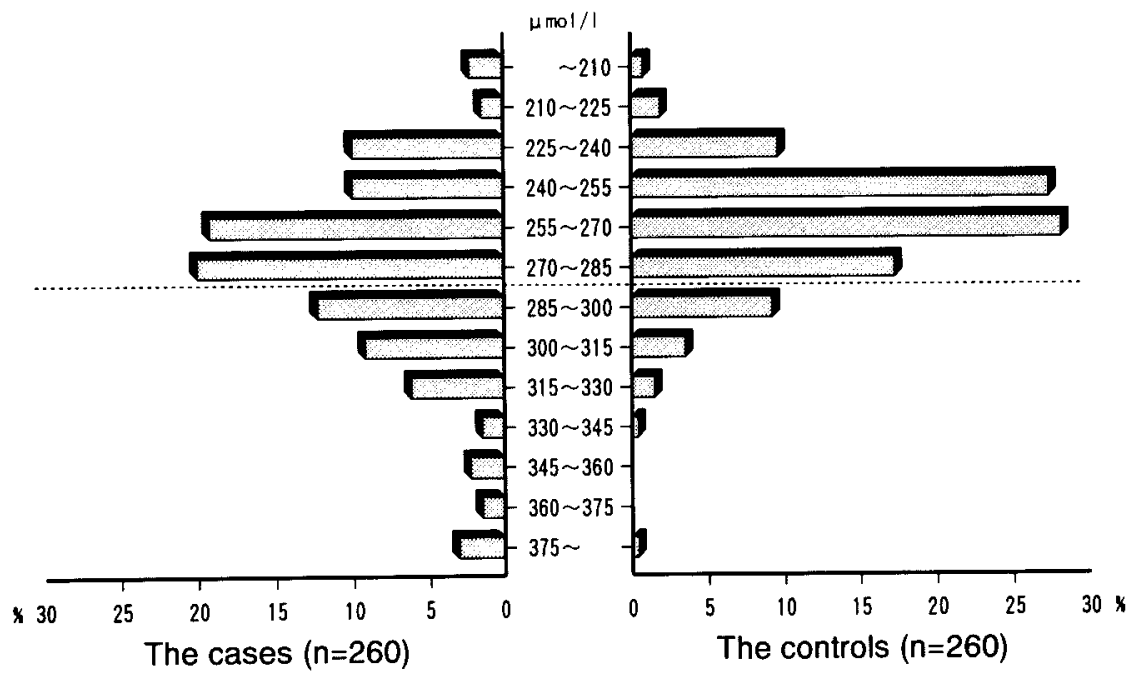

Figure 1. Distributions of serum fructosamine levels. Dotted line indicates $285 \mu \mathrm{mol} / \mathrm{l}$ which is the value of mean plus one standard deviation of the controls.

Table 2. Profile of coronary risk factors in the cases $(n=130)$ and the controls $(n=260)$.

\begin{tabular}{lccl}
\hline \multicolumn{1}{c}{ Coronary risk factors } & Cases & Controls & $\mathrm{p}$ \\
\hline Past history of diabetes millitus & $8.5 \%$ & $6.9 \%$ & $\mathrm{~ns}$ \\
Hyperfructosaminemia & $36.2 \%$ & $15.0 \%$ & $<0.01$ \\
Hypercholesterolemia & $23.1 \%$ & $25.8 \%$ & $\mathrm{~ns}$ \\
Hypo-HDL-cholesterolemia & $73.8 \%$ & $34.2 \%$ & $<0.01$ \\
Smoking & $92.3 \%$ & $74.6 \%$ & $<0.01$ \\
Obesity & $22.4 \%$ & $14.8 \%$ & $<0.10$ \\
Past history of hypertension & $43.1 \%$ & $19.6 \%$ & $<0.01$ \\
Family history of ischemic heart disease & $15.4 \%$ & $7.3 \%$ & $<0.05$ \\
\hline
\end{tabular}

Five cases and four controls were excluned for comparison of the frequency of obesity because of a lack of information about their height and/or weight. 
cases $(p<0.10)$ but that of hypercholesterolemics was not different between the two groups.

When frequency of hyperfructosaminemics was compared between subgroups with and without the past history of DM, they occupied the major part of the subgroup with the past history both in the cases $(81.8 \%)$ and in the controls $(61.1 \%)$. These percentages were significantly higher $(p<0.01)$ than the respective ones observed in the cases $(31.9 \%)$ and in the controls (11.6\%) of the subgroup without a past history (Table 3).

In a multiple logistic regression analysis in which

Table 3. Frequency of hyperfructosaminemia (\%) in the subgroup with or without a past history of diabetes mellitus.

\begin{tabular}{|c|c|c|c|}
\hline & \multicolumn{2}{|c|}{ Past history of diabetes mellitus } & \multirow{2}{*}{$\mathbf{p}$} \\
\hline & with (n) & wituout (n) & \\
\hline Cases & $81.8 \%(9 / 11)$ & $31.9 \%(38 / 119)$ & $<0.01$ \\
\hline Controls & $61.1 \%(11 / 18)$ & $11.6 \%(28 / 242)$ & $<0.01$ \\
\hline
\end{tabular}

confounding effects by other risk factors were adjusted, the odds ratio of a past history of DM $(1.19,95 \%$ confidence interval $(\mathrm{CI}): 0.47 \sim 3.03$ ) was not significant as shown in the column of Model 1 of Table 4. On the contrary, when hyperfructosaminemia was entered into the regression model instead of a past history of DM, the odds ratio $(3.59$, 95\% CI : 1.94 $\sim 6.65$ ) took a significant value as shown in the column of Model 2 in Table 4.

The same analyses were done for subgroups classified by age. Frequency of a past history of DM was significantly higher in the cases $(7.0 \%)$ than in the controls $(0.0 \%, \mathrm{p}<0.05)$ of the young men, but it was not different between the cases $(9.2 \%)$ and the controls (10.3\%) of the elderly men (Table 5). However, frequency of hyperfructosaminemics was significantly higher in the cases than in the controls both in the young $(41.9 \%$ vs. $5.8 \%, \mathrm{p}<0.01)$ and the elderly subgroups $(33.3 \%$ vs. $19.5 \%, \mathrm{p}<0.05)$. The odds ratio of hyperfructosaminemics of both the young men $(18.70$, 95\% CI : $3.34 \sim 104.64)$ and the elderly men $(2.51,95 \%$ CI : $1.22 \sim 5.18$ ) was significant in the multiple logistic regression analysis (Table 6) in which the same explan-

Table 4. Results of multiple logistic regression analysis.

\begin{tabular}{|c|c|c|c|c|}
\hline & \multicolumn{2}{|c|}{ Model 1} & \multicolumn{2}{|c|}{ Model 2} \\
\hline & $\begin{array}{l}\text { Standardized } \\
\text { coefficient }\end{array}$ & $\begin{array}{l}\text { Odds ratio ( } 95 \% \\
\text { confidence interval) }\end{array}$ & $\begin{array}{l}\text { Standardized } \\
\text { coefficient }\end{array}$ & $\begin{array}{l}\text { Odds ratio ( } 95 \% \\
\text { confidence interval) }\end{array}$ \\
\hline Past history of diabetes mellitus & 0.05 & $1.19(0.47 \sim 3.03)$ & - & - \\
\hline Hyperfructosaminemia & - & - & 0.53 & $3.59(1.94 \sim 6.65)$ \\
\hline Hypercholesterolemia & -0.11 & $0.77(0.43 \sim 1.40)$ & -0.16 & $0.69(0.37 \sim 1.27)$ \\
\hline Hypo-HDL-cholesterolemia & 0.88 & $5.86(3.47 \sim 9.89)$ & 0.92 & $6.34(3.68 \sim 10.92)$ \\
\hline Smoking habit & 0.62 & $4.75(2.13 \sim 10.57)$ & 0.63 & $4.93(2.17 \sim 11.19)$ \\
\hline Obesity & 0.11 & $1.35(0.72 \sim 2.53)$ & 0.13 & $1.42(0.75 \sim 2.70)$ \\
\hline Past history of hypertension & 0.62 & $3.94(2.27 \sim 6.84)$ & 0.53 & $3.29(1.87 \sim 5.80)$ \\
\hline Family history of ischmic heart disease & 0.13 & $1.55(0.62 \sim 3.85)$ & 0.08 & $1.29(0.57 \sim 2.89)$ \\
\hline
\end{tabular}

The number of subjects was 125 in the cases and 256 in the controls

Table 5. Profile of coronary risk factors in the cases and controls of the subgroups classified by age.

\begin{tabular}{|c|c|c|c|c|c|c|}
\hline \multirow[b]{2}{*}{ Coronary risk factors } & \multicolumn{3}{|c|}{ Young men aged 40 years or less } & \multicolumn{3}{|c|}{ Elderly men aged 41 to 60 years } \\
\hline & $\begin{array}{c}\text { Cases } \\
(n=43)\end{array}$ & $\begin{array}{l}\text { Controls } \\
(n=86)\end{array}$ & $\mathrm{p}$ & $\begin{array}{c}\text { Cases } \\
(\mathrm{n}=87)\end{array}$ & $\begin{array}{l}\text { Controls } \\
(n=174)\end{array}$ & $\mathrm{p}$ \\
\hline Age (years ; mean \pm standard deviation) & $37.2 \pm 3.0$ & $37.0 \pm 2.8$ & ns & $54.0 \pm 4.9$ & $53.7 \pm 4.9$ & ns \\
\hline Past history of diabetes mellitus & $7.0 \%$ & $0.0 \%$ & $<0.05^{1)}$ & $9.2 \%$ & $10.3 \%$ & ns \\
\hline Hyperfructosaminemia & $41.9 \%$ & $5.8 \%$ & $<0.01$ & $33.3 \%$ & $19.5 \%$ & $<0.05$ \\
\hline Hypercholesterolemia & $25.6 \%$ & $15.1 \%$ & ns & $21.8 \%$ & $31.0 \%$ & $\mathrm{~ns}$ \\
\hline Hypo-HDL-cholesterolemia & $72.1 \%$ & $38.4 \%$ & $<0.01$ & $74.7 \%$ & $32.2 \%$ & $<0.01$ \\
\hline Smoking & $97.7 \%$ & $69.8 \%$ & $<0.01$ & $89.7 \%$ & $53.5 \%$ & $<0.05$ \\
\hline Obesity & $27.9 \%$ & $14.1 \%$ & $<0.10$ & $18.4 \%$ & $14.9 \%$ & ns \\
\hline Past history of hypertension & $30.2 \%$ & $4.7 \%$ & $<0.01$ & $49.4 \%$ & $27.0 \%$ & $<0.05$ \\
\hline Family history of ischemic heart disease & $14.0 \%$ & $4.7 \%$ & ns & $16.1 \%$ & $4.6 \%$ & ns \\
\hline
\end{tabular}

One control of young men and five cases and three controls of elderly men were excluded for comparison of the frequency of obesity because of the same reason as in Table 1 .

1) By Fisher's exact probability test. 
Table 6. Results of multiple logistic regression analysis (model 2) among each subgroup classified by age.

\begin{tabular}{lcccc}
\hline \multicolumn{1}{c}{ Explanatory variables } & \multicolumn{2}{c}{ Young men aged 40 years or less } & \multicolumn{2}{c}{ Elderly men aged 41 to 60 years } \\
\cline { 2 - 5 } & $\begin{array}{c}\text { Standardized } \\
\text { coefficient }\end{array}$ & $\begin{array}{c}\text { Odds ratio }(95 \% \\
\text { confidence interval) }\end{array}$ & $\begin{array}{c}\text { Standardized } \\
\text { coefficient }\end{array}$ & $\begin{array}{c}\text { Odds ratio (95\% } \\
\text { confidence interval) }\end{array}$ \\
\hline Hoperfructosaminemia & 1.13 & $18.70(3.34 \sim 104.64)$ & 0.40 & $2.51(1.22 \sim 5.18)$ \\
Hopercholesterolemia & -0.06 & $0.85(0.22 \sim 3.31)$ & -0.18 & $0.67(0.32 \sim 1.40)$ \\
Hypo-HDL-cholesterolemia & 0.76 & $4.57(1.59 \sim 13.15)$ & 1.02 & $7.71(3.91 \sim 15.20)$ \\
Smoking habit & 1.60 & $49.99(3.87 \sim 645.23)$ & 0.40 & $2.77(1.09 \sim 7.07)$ \\
Obesity & 0.03 & $1.09(0.31 \sim 3.80)$ & 0.13 & $1.42(0.64 \sim 3.17)$ \\
Past history of hypertension & 0.69 & $7.65(1.17 \sim 50.27)$ & 0.62 & $3.65(1.89 \sim 7.09)$ \\
Family history of ischemic heart disease & 0.13 & $1.64(0.29 \sim 9.33)$ & 0.07 & $1.02(0.39 \sim 2.65)$ \\
\hline
\end{tabular}

The number of subjects was 43 in the cases and 85 in the controls among the young men, and 82 in the cases and 171 in the controls among the enderly men

atory variables as used in the whole group were entered.

\section{DISCUSSION}

Serum fructosamine concentration has been used as a short term indicator of blood glucose level for the control of $\mathrm{DM}^{6-8)}$. In addition, serum fructosamine concentration has been proven to be significantly higher in diabetics than in normoglycemics ${ }^{6}$. Therefore, it would be useful to employ serum fructosamine concentration to estimate the glucose metabolism abnormality.

In previous studies ${ }^{2,3)}$ impaired glucose tolerance, a milder form of hyperglycemia than DM, was shown to be a coronary risk factor as well. Hence we set the cut off level of hyperfructosaminemia at a relatively low point, i.e., mean plus one standard deviation of the control subjects. Hyperfructosaminemics screened by this method in those with a past history of DM accounted for more than $80 \%$ of the cases and $60 \%$ of the controls. Although these percentages were significantly higher than the respective values of those who had no past history of DM, hyperfructosaminemics occupied $32 \%$ of the cases and $12 \%$ of the controls even in the latter group. This result supports that not only DM but also a milder form or a latent state of glucose metabolism abnormality could be screened as hyperfructosaminemia by our criteria.

When we obtained the odds ratio, hyperfructosaminemia was approved as an independent risk factor for coronary artery disease, whereas a past history of DM was not. In our previous study ${ }^{5)}$ DM did not show a significant odds ratio as a coronary risk factor in the elderly men. In that study, the presence of DM was judged not only by a past history of DM but also by a fasting blood glucose level or by the result of an oral glucose tolerance test. However, not all the cases and none of the controls were subjected to the latter two tests. Despite such a situation which would have caused an overestimation of risk of DM, the odds ratio was insignificant. In this study, however, hyperfructosaminemia was approved as a coronary risk factor in the elderly group, too. These findings would indicate that in assessment of coronary risk status, hyperfructosaminemia is a better index than the information based on a past history and either fasting blood glucose level or an oral glucose tolerance test performed non-uniformly.

The oral glucose tolerance test has been an established method to diagnose the abnormal glucose metabolism, and the abnormal result in this test has been proven to be a potent risk factor for coronary artery disease ${ }^{2,3)}$. This test is also useful in evaluating resistivity of insulin response which has also shown to be a risk factor for coronary artery diseases ${ }^{9,10)}$. However, this method requires a fairly long time of fasting before application and needs two hours until completion of the test. Therefore, it is difficult to be utilized in a health check-up for a large population. On the other hand, concentration of fructosamine in the serum and glycosylated hemoglobin components of total hemoglobin ${ }^{20)}$, which are indicators of glycosylation of protein, can be determined in the blood sample obtained from non fasting subjects. Furthermore, concentration of fructosamine can be determined in the stored serum. Therefore, it is easily applicable to a health check-up of a large population.

Recently, glycosylation or glycation of various proteins is considered to play an important role in the genesis of atherosclerosis ${ }^{11-19}$. Since serum fructosamine concentration reflects the total concentration of all types of glycosylated protein in the serum, it is possible that serum fructosamine concentration is related to the amount of such atherogenic glycosylated proteins. If so, hyperfructosaminemia may become an index to assess atherogenecity itself apart from an index for hyperglycemia. 
Although, it was not clear whether the controls in this study represented general population in every aspect, at least mean and standard deviation of BMI, an index of obesity which would strongly influence the glucose metabolism ${ }^{21}$, of the controls were almost the same as those of Japanese population of the same age group ${ }^{22)}$. However, we could not deny the possibility that the controls were chosen by chance from the population whose serum fructosamine level were relatively low, because a nationwide survey of serum fructosamine level using the same kit used in this study has not been performed yet. Although hyperfructosaminemia was defined as the serum concentration of fructosamine being $285 \mu \mathrm{mol} / 1$ or higher for the sake of convenience in this study, its validity has not yet been confirmed. The appropriate cut off level of hyperfructosaminemia also has to be established in the future.

In addition, we could not exclude effects of drugs, such as diuretics or $\beta$-blockade ${ }^{23)}$, on glucose metabolism in the cases. Moreover, some drugs might have directly elevated serum fructosamine level. These problems will have to be solved in the future to confirm the usefulness of serum fructosamine for the evaluation of coronary risk state.

\section{REFERENCES}

1. Garcia MJ, McNamara PM, Gordon, T, Kannell WB. Morbidity and mortality in diabetics in the Framingham population, sixteen year follow-up study, Diabetes, 1974; 23: 105-111.

2. Fuller JH, Shipley MJ, Rose G, Jarrett RJ, Keen H. Coronary-heart-disease risk and impaired glucose tolerance, the Whitehall study. Lancet, 1980; 1: 1373-1376.

3. Donahue RP, Abbott RD, Reed DM, Yano K. Postchallenge glucose concentration and coronary heart disease in men of Japanese ancestry, Honolulu heart program. Diabetes, $1987 ; 36: 689-692$

4. Obata A, Toyoshima H, Hayashi S, et al. Risk factors for coronary atherosclerosis in young Japanese adult men. J Jpn Assoc Cerebro-Cardiovascular Dis control, 1991; 26 : 87-93.

5. Obata A. Reference in coronary risk factors of coronary atherosclerosis between younger and elder men. Niigata Med J 1992; 106: 594-602.

6. Kennedy L, Mehl TD, Riley WJ, Merimee TJ. Nonenzymatically glycosylated serum protein in diabetes mellitus, an index of short-term glycaemia. Diabetologia, $1981 ; 21: 94-98$.

7. Kennedy AL, Merimee TJ Glycosylated serum protein and hemoglobin $A_{1}$ levels to measure control of glycemia. Ann Intern Med, 1981; 95 : 56-58.

8. Johnson RN, Metcalf PA, Baker JR. Fructosamine : a new approach to the estimation of serum glycosylprotein. An index of diabetic control. Clin Chim Acta, 1982; 127 : 87-95.
9. Stout RW. Insulin and Atheroma, -an update. Lancet, 1987; 1: 1077-1079.

10. Fontbonne A, Charles MA, Thibult N, et al. Hyperinsulinaemia as a predictor of coronary heart disease mortality in a healthy population: the Paris prospective study, 15-year follow-up. Diabetologia, 1991; 34 : 356-61.

11. Witztum JL, Mahoney EM, Branks MJ, Fisher M, Elam R, Steinberg D. Nonenzymatic glucosylation of low-density lipoprotein alters its biologic activity. Diabetes, 1982; 31 : 283-291.

12. Lopes-Virella MF, Klein RL, Lyons TJ, et al. Glycosylation of low-density lipoprotein enhances cholesteryl ester synthesis in human monocyte-derived macrophages. Diabetes, 1988 ; 37 : 550-557.

13. Sobenin IA, Tertov VV, Orekhov AN, Smirnov VN. Synergetic effect of desialylated and glycated low density lipoproteins on cholesterol accumulation in cultured smooth muscle intimal cells. Atherosclerosis, 1991; 89: 151-154.

14. Ishii $H$, Umeda F, Kunisaki M, Yamauchi T, Nawata $H$. Modification of prostaglandin synthesis in washed human platelets and cultured bovine aortic endothelial cells by glycosylated low density lipoprotein. Diabetes Res, 1989; 12: 177-182.

15. Duell PB, Oram JF, Bierman EL. Nonenzymatic glycosylation of HDL and impaired HDL-receptormediated cholesterol efflux. Diabetes, $1991 ; 40: 377-$ 384.

16. Duell PB, Oram JF, Bierman EL. Nonenzymatic glycosylation of HDL resulting in inhibition of highaffinity binding to cultured human fibroblasts. Diabetes, 1990; 39: 1257-1263.

17. Brownlee M, Cerami A, Vlassara $H$. Advanced glycosylation end products in tissue and the biochemical basis of diabetic complications. $N$ Engl J Med, 1988; 318: 1315-1321.

18. Mullarkey CJ, Edelstein D, Brownlee M. Free radical generation by early glycation products: a mechanism for accelerated atherogenesis in diabetes. Biochem Biophys Res Commun 1990; 173 : 932-939.

19. Kirstein M, Brett J, Radoff S, Ogawa S, Stern D, Vlassara H. Advanced protein glycosylation induces transendothelial human monocyte chemotaxis and secretion of platelet-derived growth factor: role in vascular disease of diabetes and aging. Proc Natl Acad Sci USA, 1990; 87: 9010-9014.

20. Gabbay KH, Hasty K, Breslow JL, et al. Glycosylated hemoglobins and long-term blood glucose control in diabetes mellitus. J Clin Endocrinol Metabol, 1977; 44 : 859-864.

21. National Diabetes Data Group: Classification and diagnosis of diabetes mellitus and other categories of glucose intolerance. Diabetes $1979 ; 28$ : 1039-1057.

22. Health promote and nutrition division, health surveys bureau, ministry of health and welfare. Recommended dietary allowances for the Japanese. The 4th revision. $p$ 124-130, Tokyo, Daiichi Shuppan Publichers, 1989 (in Japanese).

23. Bengtsson $\mathrm{C}$, Blohme $\mathrm{G}$, Lapidus $\mathrm{L}$, et al. Do antihypertensive drugs precipitate diabetes? Br Med J, 1984; 289 : 1495-1497. 